\title{
A Pilot Study on Home Range and Habitat Use of Chinese Goral (Naemorhedus Griseus): Exploring GPS Tracking Data in Cliff Landscape by Three Estimation Methods
}

\author{
Yang Teng \\ Beijing Forestry University \\ Shupei TANG \\ Sichuan Academy of Environmental Policy Research and Planning \\ Dalai Menghe \\ Northeast Forestry University \\ Liji Wu \\ Inner Mongolia Saihanwula National Nature Reserve Administration \\ Zhiqing HAN \\ Inner Mongolia Saihanwula National Nature Reserve Administration \\ Yingying HAN \\ Beijing Forestry University \\ Weidong BAO ( $\square$ wdbao@bjfu.edu.cn ) \\ Beijing Forestry University
}

\section{Research Article}

Keywords: Chinese goral, home range, minimum convex polygon, kernel density estimation, a-local convex hull

Posted Date: July 19th, 2021

DOI: https://doi.org/10.21203/rs.3.rs-597882/v2

License: (c) (1) This work is licensed under a Creative Commons Attribution 4.0 International License. Read Full License 


\section{Abstract}

Home range size estimation is a crucial basis for developing effective conservation strategies and provides important insights into animal behavior and ecology. This study aimed at analyzing the home range variations, the influence of altitude in habitat selection, and comparing three methods in home range estimation of Chinese gorals (Naemorhedus griseus) living at a cliff landscape. The results indicated that there were significant differences between the annual home range sizes of individual animals but there was no difference in their seasonal home range sizes based on GPS tracking data of five female Chinese gorals from February 2015 to September 2018. The monthly home ranges decreased dramatically in May, June and July due to birth-giving. Notable seasonal variations were found in the micro-habitats of the Chinese gorals, as reflected by the altitude they inhabit, with higher altitude habitats used in spring and lower altitude habitats used in winter. Additionally, the altitude of monthly habitats was lowest in January, which may indicate an adaptation to low air temperature. We also found differences between estimation methods, namely minimum convex polygon (MCP), kernel density estimation (KDE) and a-local convex hull ( $\mathrm{a}-\mathrm{LOCOH})$, with seasonal home range sizes derived from aLoCoH being substantially smaller than those derived from MCP and KDE. In conclusion, our findings filled the gaps in home range study for this endangered species and contributed to effective conservation strategies. Considerations shall have to be given to the variations in home range estimation caused by different methods when dealing with rugged habitats, so as to make sure that any interpretation concerning the habitat use of the targeted species made on basis of such results would be meaningful and valid.

\section{Introduction}

Home range is defined as the area traversed by an individual during its normal activities of feeding, mating and caring for its offspring (Burt 1943). It provides a variety of necessary natural resources and conditions for wild animals (Gareshelis 2000), studies on animal home range variation can shed lights on the distribution and utilization of resources, and habitat selection in time and space, hence contributing to better understanding about animal behavior and ecology (Pebsworth et al. 2012; Noonan et al. 2018). Previous studies had shown that ecological factors such as the condition of the animal itself, food in the habitat, topography and shelter conditions can all affect the size of the home range (Bowers et al 1996; Guarino 2002). The characteristics of home range, such as spatial distribution, shape and home range overlap, have their specific formation causes and potential biological significance. Meanwhile, home range size is an important parameter for estimating the minimum active area needed to predict the habitat carrying capacity (Baber 2003) that is valuable in managing the minimum viable populations (Kang and Paek 2005) and developing effective conservation strategies (Macdonald 2016; Wilson et al. 2018).

The basis of home range analysis is the collection of activity sites of the studied animals. GPS tracking provides convenience for site location and consequently has obvious advantages over other data collection methods in animal spatial behavior study (Walter et al. 2015). The most important advantage 
of GPS tracking seems to be the continuous recording of locations during study period, and providing large number of accurate locations that may be obtainable without interfering the normal life of animals that is being tracked (Pebsworth et al. 2012; Dvořák et al. 2014; Cohen et al. 2018).

Home range can be calculated with plenty of methods (Getz et al. 2007; Laver and Kelly 2008). These methods have different merits and weakness (Cumming and Cornélis 2012; Reinecke et al. 2014; Halbrook and Petach 2018), and no standardized method for home range analysis exists (Signer and Balkenhol 2015). Minimum convex polygon (MCP) is a simple and most widely used method in home range estimation, but it is sensitive to outlier locations and the number of fixes, and poor fit to data if the shape of the home range is non-convex. Moreover, MCP is not capable of providing data concerning density distribution (Laver and Kelly 2008; Nilsen et al. 2008). Kernel density estimation (KDE) has been considered the most commonly used method which constructs home range based on a probability of distribution. (Wartmann et al. 2010; Lichti and Swihart 2011; Cumming and Cornélis 2012). However, home range estimates generated by KDE is difficult to compare with those resulted from other methods due to its sensitive trait to the types of smoothing schemes and no optimal process for determining the bandwidth (Hemson at al. 2005; Laver and Kelly 2008). In addition, both the MCP and KDE methods share common shortcomings, one among which is the invalid active areas, i.e. regions that animals do not frequently used (Getz and Wilmers 2004). These invalid regions might include areas containing distinct boundaries or physically inaccessible landscapes, such as steep cliffs, and fenced domains, that may not be utilized by the tracked animals (Getz et al. 2007). Fortunately, Getz et al. (2007) refined the local convex hull (LoCoH) method which preserves the simple and intuitive idea of MCP and introduced the concept of contours in $\mathrm{KDE}$, which solved the problem of sensitivity to abnormal points in the MCP and addressed the problem of invalid areas.

The Chinese goral (Naemorhedus griseus) is a small ungulate with a goat-like appearance that inhabits steep rocky terrain and timberland throughout the northern, central, and southern parts of China (Hrabina 2015; Liu and Zhang 2018). In its northern distribution, the Chinese gorals normally favor steep slopes as shelters to avoid predators and may move to lower altitude areas in cold season (Chen et al. 2012; Yang et al. 2019). It is categorized as the second class of state key protected species in China, a vulnerable

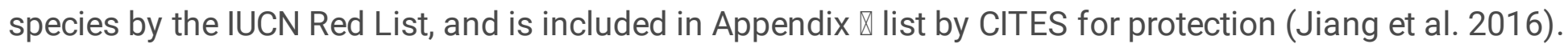
The goral population in Saihanwula National Nature Reserve in Inner Mongolia was the source population of this area in the 1960s and 1970s, and the surrounding small populations mainly came from this population (National Forestry Administration 2009; Liu and Zhang 2018). Under the disturbance of increased human activities in this region, the surrounding small populations had disappeared and the source population had also been further isolated and localized in this nature reserve. Therefore, understanding its basic ecological traits and behavior is critical in planning appropriate conservation measures. Previous studies have focused on observations of diet analysis, habitat suitability assessment and preliminary molecular biology (Zhou 2015; Tang et al. 2018; 2019; Liu and Zhang 2018), but there is no report on home range estimation for this species. 
The Chinese goral population in Saihanwula National Nature Reserve of Inner Mongolia lived in a limited cliff landscape which was isolated from the populations in central China (Tang et al. 2019). In addition, a study found that this goral population maintained a moderate genetic diversity and diverged with its southern conspecifics in Beijing region (Yang et al. 2019). Therefore, revealing the goral's adaptation strategy to limited space resources, and clarifying the overlapping use and segmentation behavior of home range and microhabitat spaces are of great significance to effectively protect and improve the quality of animal habitats. This study aimed to detect home range variations of the gorals by GPS tracking and select a better data analysis method in the rugged terrain environment which would be helpful for the conservation of this isolated population.

\section{Materials And Methods}

\section{Study areas}

We conducted fieldwork in the Saihanwula National Nature Reserve ( $\left.118^{\circ} 18^{\prime}-118^{\circ} 55^{\prime} \mathrm{E}, 43^{\circ} 59^{\prime}-44^{\circ} 27^{\prime} \mathrm{N}\right)$, which is located in the southern part of Greater Khingan Mountains, Inner Mongolia, China (Fig. 1). The nature reserve covers about $1000 \mathrm{~km}^{2}$ and has elevations varied from 846 to $1933 \mathrm{~m}$. The climate of the study area belongs to temperate semiarid environment marked by long cold winter and short hot summer, with the annual air temperature standing approximately around $2^{\circ} \mathrm{C}$ (Zheng et al. 2015; Dai et al. 2018). The mammal species in the study area include Eurasian lynx (Lynx lynx), leopard cat (Prionailurus bengalensis), gray wolf (Canis lupus), red fox (Vulpes vulpes), raccoon dog (Nyctereutes procyonoides), red deer (Cervus elaphus), roe deer (Capreolus pygarus), wild boar (Sus scrofa) and Chinese goral. The suitable habitat of the goral is mainly distributed in south and central part of the nature reserve (Tang et al. 2019), which is isolated from other goral populations.

\section{Capture and collaring of gorals}

The tracking period lasted from February 2015 to September 2018. The gorals were captured using salt baited falling traps with safety protection net in the midway of the trap, after capturing the animals were aged by tooth eruption and weights (Table 1).

Table 1

Information of captured gorals and GPS tracking period

\begin{tabular}{|llllll|}
\hline Individual & No. collars & Sex & Age & Weight(kg) & Observation period(month) \\
\hline CG01 & 16134 & Female & $1-2$ & 16.98 & $2016.01-2018.09(33)$ \\
\hline CG02 & 16135 & Female & $1-2$ & 15.98 & $2015.03-2018.07(37)$ \\
\hline CG03 & 16138 & Female & $2-4$ & 33.88 & $2015.12-2018.09(34)$ \\
\hline CG04 & 16139 & Female & $3-5$ & 28.95 & $2015.07-2018.09(39)$ \\
\hline CG05 & 16140 & Female & $2-4$ & 26.54 & $2015.02-2015.03(02)$ \\
\hline
\end{tabular}


The gorals were fitted with GPS collars (GPS Plus with VHF communication collar, Vectronic Aerospace, Germany, collar details are available from the manufacturer: see https://www.vectronic-aerospace.com/) programmed with two locations per day (8:00 a.m. and 8:00 p.m. local time). Through the data landing software platform (GPS PlusX v10.0.24) the positional data, including date, time, latitude, longitude, altitude, position dilution of precision (PDOP) were downloaded. Fixes within the first 10 days following the capture were omitted from the analyses (Witey et al. 2001) and only 3-dimensional locations with PDOP $\leq 10 \mathrm{~m}$ were used to remove the less accurate locations (Adrados et al. 2002). We captured five females for this study and one of them was killed by lynx three months after collaring, so the GPS location data for this individual (CG05) was only used for monthly home range analysis. All aspects of animal capture protocol were duly approved by the Forestry Department of Inner Mongolia Autonomous Region (Document No 2015 - 414). According to the local climate conditions, we defined March to May as spring season, June to August as summer, with September and October, and November to the following February as autumn and winter respectively.

Ethics statement: All the animal ethics issues and experimental protocols mentioned in this article have been approved by the Inner Mongolia Forestry Department, and the permission to enter Saihanwula Nature Reserve in Inner Mongolia has also been obtained. In addition, there was no animal injury or death in all the experimental procedures, and the Biosafety Committee of Inner Mongolia Forestry Department considered that there were no animal ethics issues involved. The study was carried out in accordance with ARRIVE guidelines.

\section{Home range estimation}

We calculated MCP and KDE using reference bandwidths, and a-LoCoH home ranges using the "rhr" (Version 1.2.909, Signer and Balkenhol 2015) in R (Version 3.5.3, 2019-03-11, R Core Team 2019). The aLoCoH method begins by locating all neighbors that can be attained a distance $\mathrm{a}$, constructs a convex hull for each relocation and its nearest neighbors, and incrementally merges the hulls together from smallest to largest into isopleths (contours) (e.g. $95 \%$ or $50 \%$ ). Here, we applied a-LoCoH estimation as implemented in the R package "rhr" with the value of the tuning parameter a defined as the maximum distance between any two locations (Getz and Wilmers 2004; Getz et al. 2007; Signer and Balkenhol 2015). We tracked four goral (CG01, CG02, CG03 and CG04) for over two years, the extent of $95 \%$ and $50 \%$ annual home ranges, and the $95 \%$ isopleth seasonal home ranges were estimated by the three methods. Thus, there were six (one home range with three different estimators by $95 \%$ and $50 \%$ contours) to twelve (two annual home ranges with six different estimators) different cases of annual home ranges for each individual goral $(n=4)$. Overall, we computed 48 annual home range sizes and 138 seasonal home range sizes. In addition, we estimated the extent of monthly home range sizes by $95 \% \mathrm{MCP}$, so there were 145 monthly home range sizes with five goral being calculated.

Home range sizes were log-transformed to meet the assumptions of normality. We used analysis of threeway ANOVA to compare the inter-individual differences and annual home range estimations from different methods at $95 \%$ and $50 \%$ contour variances, and seasonal and monthly differences in home range sizes. The data of altitudes were not normally distributed, nor were the variances homogeneous, so 
non-parametric analyzes of Kruskal-Wallis and Wilcoxon rank sum tests were used to compare differences in seasonal habitat use in altitude variations. All data were expressed as mean \pm standard deviation, and $a=0.05$ as significant for statistical tests.

\section{Results}

\section{Annual home range variation}

The annual home range of the four Chinese goral was $0.205 \pm 0.138 \mathrm{~km}^{2}$ (MCP 95\%), $0.038 \pm 0.022 \mathrm{~km}^{2}$ (MCP 50\%), $0.256 \pm 0.166 \mathrm{~km}^{2}$ (KDE 95\%), $0.053 \pm 0.034 \mathrm{~km}^{2}$ (KDE 50\%), $0.099 \pm 0.05 \mathrm{~km}^{2}$ (a-LoCoH $95 \%), 0.022 \pm 0.012 \mathrm{~km}^{2}$ (a-LoCoH 50\%), with CG03 having the smallest home range sizes during the study period (Table 2 ).

Table 2

Annual home ranges of four Chinese gorals by three different methods

\begin{tabular}{|c|c|c|c|c|c|c|c|c|}
\hline \multirow[t]{2}{*}{ Individual } & \multirow[t]{2}{*}{ Year } & \multirow[t]{2}{*}{ Num $^{\mathrm{a}}$} & \multicolumn{2}{|c|}{$\mathrm{MCP}\left(\mathrm{km}^{2}\right)$} & \multicolumn{2}{|c|}{$\mathrm{KDE}\left(\mathrm{km}^{2}\right)$} & \multicolumn{2}{|c|}{ a-LoCoH $\left(\mathrm{km}^{2}\right)$} \\
\hline & & & $95 \%$ & $50 \%$ & $95 \%$ & $50 \%$ & $95 \%$ & $50 \%$ \\
\hline \multirow[t]{2}{*}{ CG01 } & 2016 & 494 & 0.124 & 0.027 & 0.140 & 0.033 & 0.081 & 0.019 \\
\hline & 2017 & 397 & 0.136 & 0.029 & 0.178 & 0.038 & 0.083 & 0.023 \\
\hline \multirow[t]{2}{*}{ CG02 } & 2016 & 550 & 0.403 & 0.061 & 0.478 & 0.095 & 0.181 & 0.042 \\
\hline & 2017 & 447 & 0.387 & 0.079 & 0.487 & 0.109 & 0.159 & 0.039 \\
\hline \multirow[t]{2}{*}{ CG03 } & 2016 & 444 & 0.055 & 0.017 & 0.073 & 0.018 & 0.044 & 0.010 \\
\hline & 2017 & 368 & 0.048 & 0.016 & 0.076 & 0.017 & 0.039 & 0.008 \\
\hline \multirow[t]{2}{*}{ CG04 } & 2016 & 555 & 0.234 & 0.040 & 0.290 & 0.052 & 0.106 & 0.019 \\
\hline & 2017 & 499 & 0.253 & 0.039 & 0.323 & 0.058 & 0.101 & 0.019 \\
\hline
\end{tabular}

A comparison of all log-transform annual home range sizes obtained from the three methods showed that home ranges differed significantly from each other both at $95 \%$ and $50 \%$ contours (MCP 95\%: $\mathrm{F}=$ 341.2, $d f=3, P<0.001 ; K D E$ 95\%: $F=150.3, P<0.001 ; a-L o C o H ~ 95 \%: F=159, P<0.001 ; M C P ~ 50 \%: F=$ 68.82, $d f=3, P<0.001 ; K D E 50 \%: F=154.1, P<0.001 ; a-L o C o H ~ 50 \%: F=122, P<0.001$ ), which varied by nearly 8.4-fold (e.g. the home range size of CG02 at 2016 and CG03 at 2017 at the $95 \%$ contour for MCP was $0.403 / 0.048$ ). There were significant differences among three methods ( $M C P, K D E$ and $a-L o C o H)$ in annual home ranges ( $95 \%$ contour: $d f=2, F=235.596, P<0.001 ; 50 \%$ contour: $F=3.509, d f=2, P=0.048$ ), 
and the estimations from the a-LoCoH method were normally the smallest compared with those generated by the MCP and KDE methods (Fig. 2).

\section{Seasonal home range variation}

The seasonal variation in home ranges were not significant by ANOVA $(F=0.07, d f=3, P=0.975)$, with home range in MCP $95 \%$ being $0.165 \pm 0.155 \mathrm{~km}^{2}$ in spring, $0.151 \pm 0.125 \mathrm{~km}^{2}$ in summer, $0.142 \pm 0.089$ $\mathrm{km}^{2}$ in autumn, and $0.155 \pm 0.112 \mathrm{~km}^{2}$ in winter. However, significant differences between each of the methods were found (MCP, KDE and $a-\mathrm{LoCoH})$ in seasonal home range size $(F=32.41, d f=2, P<0.001)$, with estimates obtained from the a-LoCoH method being the smallest $\left(0.064 \pm 0.038 \mathrm{~km}^{2}\right)$, much less than those obtained from the MCP $\left(0.153 \pm 0.122 \mathrm{~km}^{2}\right)$ and KDE $\left(0.224 \pm 0.160 \mathrm{~km}^{2}\right)$ methods.

\section{Monthly home range variation}

As to the monthly home ranges of the Chinese gorals by MCP $95 \%$, no significant difference was found between the tracked animals $(n=5)(F=0.451, d f=11, P=0.93)$. The smallest home range was observed in February $\left(0.054 \pm 0.032 \mathrm{~km}^{2}\right)$, while larger home ranges were observed from August to December. Five goral increased their home range sizes from February to April, however, the home ranges dramatically decreased during the period ranging from May, June through July (Fig. 3).

\section{Use of habitats at different altitudes}

Using altitude data from GPS collar recording, we analyzed the use of habitats in different altitudes. Four gorals used habitats with a mean altitude of $1444.54 \pm 56.79 \mathrm{~m}$, with the highest in spring $(1450.99 \pm$ $56.08 \mathrm{~m})$ and lower in winter $(1439.92 \pm 66.60 \mathrm{~m})$, summer $(1442.59 \pm 67.85 \mathrm{~m})$, and autumn $(1441.22 \pm$ $70.14 \mathrm{~m}$ ). It showed that there was significant difference over all seasons (Kolmogorov-Smirnov test: $D=$ 0.038, $\mathrm{df}=4855, \mathrm{P}<0.01$;Kruskal- Wallis $H$ test: $\left.\chi^{2}=26.776, \mathrm{df}=3, \mathrm{P}<0.01\right)$. Moreover, the monthly altitude was highest in May $(1456 \pm 59.74 \mathrm{~m})$, lowest in January $(1429.94 \pm 62.79 \mathrm{~m})$. No significant differences were found between summer and autumn $(P=1)$, summer and winter $(P=0.6)$, or autumn and winter $(P=1)$, but significant differences existed between spring and summer $(P<0.01)$, spring and autumn $(P<0.01)$, as well as between spring and winter $(P<0.001)$. Thus, four gorals tended to move to higher altitudes during the spring, particularly in May. In winter, the gorals tended to perch on loweraltitude habitats, particularly during January when the weather was the coldest.

\section{Discussion}

\section{Spatial behavior of Chinese goral}

In spite of the relatively small sample used for this study, it marked the first attempt to make a comprehensive analysis on the annual, seasonal and monthly home range size and altitude use of the Chinses goral with GPS collars, which contributes to providing us a better understanding about the spatial behavior for this endangered species. The annual home range sizes had considerable interindividual variation and the average home ranges varied by 8.4 -fold among the four goral in the $95 \%$ 
contour for MCP (range: $0.048 \sim 0.403 \mathrm{~km}^{2}$ ). Several hypotheses have been proposed concerning the environmental and individual factors that might affect the extent of space use of wild animals (Reinecke et al. 2014; Dvořák et al. 2014; Christiansen et al. 2017; Halbrook and Petach 2018). Drawing on existing knowledge of other ungulate species (Van et al. 2010; Morellet et al. 2013; Viana et al. 2018; Amor et al. 2019), we concluded that among the four Chinese gorals this inter-individual difference in annual home range sizes may be attributed to foraging opportunities, topographic relief, landscape heterogeneity, intrinsic factors, such as sex, age, and the internal state of the gorals, and furthermore, the influence of predation risk. Particularly, individual CG 03 had consistently kept a smaller home range than the other three gorals in this study. The reason for this notable inter-individual variation might have something to do with the different patterns in the movement of the animals, which in turn are often associated with their physiological state or even natural traits, such as being bold or timid by nature (Spiegal et al. 2017; Viana et al. 2018). In addition, some researchers speculated that smaller home ranges may lower the risk of running into predators (Wilson et al. 2018).

Herbivores' home ranges varied seasonally, which indicates an adaptation to various environmental factors, for instance, the snow depth, foraging opportunities, and environmental temperatures (Morellet et al. 2013). In winter time, poorer habitat quality, for instance heavy winter snowfalls, lack of foraging opportunities and etc., may force the animal to travel farther away from their homes to seek adequate forage and suitable covers (Seidel and Boyce 2016). In contrast, during the calving seasons, the need for caring young may reduce travelling (Vore and Schmidt 2001; Cho et al. 2016; Yan et al. 2017). But no significant differences were found in the seasonal home range variations of the Chinese goral in this study. In our study area, the forage quality and appropriate temperature changed progressively and attracted gorals to higher altitudes gradually where fresh vegetation grows timely during the spring season, which might explain the expansion to the highest altitudes and the largest home range sizes in spring. During winter times, vegetation at higher altitude becomes unavailable due to seasonal senescence and snowfalls, forcing the gorals to move downwards to comparatively favorable places at lower altitudes where vegetation can be found. There might be a trade-off between foraging and energy conserving, which explains why the second largest home range sizes occurred and the lowest use of altitudes in winter. Notably, the smallest monthly home range occurred in February in this study, when the forage resources were the scarcest in winter months. As a response to scarce resources, the Chinese goral may conserve energy by moving around less so as to compensate for the reduced food intake, which is similar to other ungulates living in mountainous environment (Luccarini et al. 2006; Yan et al. 2017). On the contrary, during summer and autumn when food resources are more stable at both higher and lower altitudes, the home range size decreased accordingly. Some researchers reported that females' home range decreased dramatically due to cub birthing (Carvalho et al. 2008; Cho et al. 2016). Our results partially supported claims that the home range decrease in females could be explained by the breeding and birth cycles, as mature female gorals showed a decrease in home range size during the period ranging from May, through July that corresponded to the birth of cubs. This was similar to long-tailed goral (N. caudatus) in their home range variations (Cho et al. 2016). On the other hands, we found that the four female gorals maintained relatively stable home ranges and showed obvious spatial overlaps, 
such as between CG01 and CG03, CG02 and CG04 (Fig. 1). Although we didn't know the detailed kinship relations among these goral, the small study area may force genetically related individuals to share suitable habitats (Yang et al. 2019), which may contribute to conservation policy planning and management of this endangered species.

\section{Methodological implications}

Due to the complexity and diversity of home range estimation methods, and the fact that there is no standardized method evaluation (Fieberg and Börger 2012; Signer and Balkenhol 2015), it is necessary to carefully match specific objectives with appropriate methods in analyzing home range sizes (Halbrook and Petach 2018). Previous studies confirmed that LoCoH was more preferable compared with MCP and $\mathrm{KDE}$, as this model produced lower statistical error rates and could more realistically describe home range size (Getz et al. 2007). However, when Lichti and Swihart (2011) compared KDE with LoCoH, the LoCoH failed to outperform KDE on some performance metrics, such as estimates of utilization distribution and projections of where that animal might occur. Furthermore, Pebsworth (2012), who used MCP, KDE and Y$\mathrm{LoCoH}$ methods to calculate home ranges, indicated that KDE model performed more accurately than the other 2 methods in creating a continuous home range boundary. Thus, no consensus has been reached concerning which home range estimator is optimal. Some researchers recommended that home range related variations caused by the selection of different methods need to be considered more cautiously (Laver and Kelly 2008; Gula and Theuerkauf 2013; Reinecke et al. 2014). Our study calculated home range size of the Chinese goral with three estimation methods, suggesting that home rang estimates based on the a-LoCoH method were smaller than those obtained by the other two methods, and home range size estimates derived with the KDE method were slightly larger than that derived with MCP method. This is similar to most other studies in which results yielded by the a-LoCoH method were much smaller than those by other methods (Getz and wilmers 2004; Huck et al. 2008; Pebsworth et al. 2012; Reinecke et al. 2014).

The a-LoCoH method can exclude unused areas, whereas MCP and KDE methods include these restricted areas that are physically inaccessible, or patches that are, though accessible, typically avoided by the studied animals (Getz et al. 2007; Reinecke et al. 2014; Walter et al. 2015). Our study area included steep cliff and canyons, which is the suitable habitat area for Chinese goral (Tang et al. 2019). Steep rocky terrain features would tend to prefer a-LoCoH method, but these features pose no obstacles to gorals movements; on the contrary, they were important shelters for reducing predation risk. Thus, it is necessary to do a study to judge the ability of a-LoCoH method to exclude potentially unused areas in habitats of this species, the cliffs and mountainous regions in this particular case. Nonetheless, with the employment of multiple methods for estimating home range sizes, accuracy would be greatly improved (Boyle et al. 2009; Reinecke et al. 2014). Hence, we suggested that future studies should provide home range estimates from a range of methods to ensure meaningful comparisons across studies. In conclusion, our study on the annual, seasonal, and monthly home range variations by three estimation methods, as well as the seasonal and monthly habitat altitude changes is critically important to better understanding of 
habitats needed by Chinese goral and can be used as fundamental data for the conservation and habitat management of this endangered species.

\section{Declarations}

\section{ACKNOWLEDGMENTS}

We would like to extend our gratitude to all the staff in the Inner Mongolia Saihanwula National Nature Reserve Administration for their valuable supports in helping us capturing and collaring the animals as well as in maintaining the habitats.

\section{References}

1. Burt, W. H. Territoriality and home range concepts as applied to mammals. Journal of Mammal, 24, 346-352 (1943).

2. Garshelis, D. L. Delusions in habitat evaluation: measuring use, selection, and importance in L. Boitani, T. K. Fuller. Research Techniques in Animal Ecology: Controversies and Consequences. 4353 (Columbia University Press,2000).

3. Pebsworth, P. A., Morgan, H. R. \& Huffman, M. A. Evaluating home range techniques: use of global positioning system (GPS) collar data from chacma baboons. Primates, 53, 345-355 (2012).

4. Noonan, M. J., Tucker, M. A. \& Fleming, C. H. Akre T. A comprehensive analysis of autocorrelation and bias in home range estimation. Ecological Monographs. 2018, e01344 (2018).

5. Bowers, M. A., Gregario, K., Brame, C. J., Matter, S. F. \& Dooley, J. L. Use of space and habitats by meadow voles at the home range, patch and landscape scales. Oecologia, 105, 107-115 (1996).

6. Guarino, F. Spatial ecology of a large carnivorous lizard, Varanus varius (Squamata: Varanidae). J. Zool. (London), 258, 449-457 (2002).

7. Baber, M. J. \& Craig, J. L. Home range size and carrying capacity of the south island takahe (Porphyrio hochstetteri) on Tiritiri Matangi Island. Notornis, 50, 67-74 (2003).

8. Kang, H. S. \& Paek, K. J. Evaluating home ranges of endangered Asiatic Black Bears for in situ conservation. Korean Journal of Ecology, 28, 395-404 (2005).

9. Macdonald, D. W. Animal behavior and its role in carnivore conservation: examples of seven deadly threats. Anim. Behav, 120, 197-209 (2016).

10. Wilson, K. S., Pond, B. A. \& Brown, G. S. The biogeography of home range size of woodland caribou Rangifer tarandus caribou. Diversity and Distributions, 25, 205-216 (2019).

11. Walter, W. D., Onorato, D. P. \& Fischer, J. W. Is there a single best estimator? Selection of home range estimators using area under the curve. Movement Ecology, 3, 10-16 (2015).

12. Dvorak, S., Bartak, V., Machacek, Z. \& Mateju, J. Home range size and spatio-temporal dynamics of male sika deer (Cervus nippon; Cervidae, Artiodactyla) in an introduced population. Folia Zool, 63, 103-116 (2014). 
13. Cohen, B. S., Prebyl, T. J., Collier, B. A. \& Chamberlain, M. J. Home range estimator method and GPS sampling schedule affect habitat selection inferences for wild turkeys. Wildlife Society Bulletin, $\mathbf{4 2 ,}$ 150-159 (2018).

14. Getz, W. M. et al. LoCoH: nonparameteric kernel methods for constructing home ranges and utilization distributions. PLoS one, 2, e207 (2007).

15. Laver, P. N. \& Kelly, M. J. A critical review of home range studies. The Journal of Wildlife Management, 72, 290-298 (2008).

16. Cumming, G. S. \& Daniel, C. Quantitative comparison and selection of home range metrics for telemetry data. Diversity and Distributions, 18, 1057-1065 (2012).

17. Reinecke, H. et al. Home range size estimates of red deer in Germany: environmental, individual and methodological correlates. European Journal of Wildlife Research, 60, 237-247 (2014).

18. Halbrook, R. S. \& Petach, M. Estimated mink home ranges using various home-range estimators. Wildlife Society Bulletin, 42, 656-666 (2018).

19. Signer, J. \& Balkenhol, N. Reproducible home ranges (rhr): a new, user-friendly R package for analyses of wildlife telemetry data. Wildlife Society Bulletin, 39, 358-363 (2015).

20. Nilsen, E. B., Pedersen, S. \& Linnell, J. D. C. Can minimum convex polygon home ranges be used to draw biologically meaningful conclusions? Ecology Research, 23, 635-639 (2008).

21. Wartmann, F. M., Purves, R. S. \& van Schaik, C. P. Modelling ranging behavior of female orang-utans: a case study in Tuanan. Central Kalimantan, Indonesia. Primates, 51, 119-130 (2010).

22. Lichti, N. I. \& Swihart, R. K. Estimating utilization distributions with kernel versus local convex hull methods. The Journal of Wildlife Management, 75, 413-422 (2011).

23. Hemson, G., Johnson, P., South, A., Kenward, R. \& Mcdonald, R. D. Are kernels the mustard? Data from global positioning system (GPS) collars suggests problems for kernel home range analyses with least-squares cross validation. Journal of Animal Ecology, 74, 455-463 (2005).

24. Getz, W. M. \& Wilmers, C. C. A local nearest-neighbor convex-hull construction of home ranges and utilization distributions. Ecography, 27, 489-505 (2004).

25. Hrabina, P. A new insight into the taxonomy and zoogeography of recent species of goral (Nemorhaedus, Bovidae, Ruminantia). Gazella, 42, 33-91 (2015).

26. Liu, Y. \& Zhang, M. The complete mitochondrial genome of Naemorhedus griseus, (Artiodactyla: Bovidae) and its phylogenetic implications. Conservation Genetics Resources, 10, 179-183 (2018).

27. Chen, W., Wu, Q. G., Hu, J. C., Lu, X. \& You, Z. Q. Seasonal habitat use of Chinese goral (Naemorhedus griseus) in a subtropical forest. Russian Journal Ecology, 43, 256-260 (2012).

28. Yang, J. et al. Non-invasive genetic analysis indicates low population connectivity in vulnerable Chinese gorals: concerns for segregated population management. Zoological Research, 40, 439-448 (2019).

29. Jiang, Z. G. et al. Red list of China's vertebrates. Biodiversity Science, 24, 500-510 (2016). 
30. National Forestry Administration. Resources Survey on Chinese Key Terrestrial Wild Animals2529(China Forestry Publishing House, 2009).

31. Zhou, X. W. Preliminary research on conservation genetics of two Chinese goral populations based on fecal DNA. Dissertation, Beijing Forestry University(2015).

32. Tang, S. P. et al. Seasonal diet analysis of Naemorhedus griseus in Saihanwula National Nature Reserve. Sichuan Journal of Zoology, 37, 311-316 (2018).

33. Tang, S. P., Mu, L. G., Zhang, J. \& Bao, W. D. Habitat suitability assessment based on MaxEnt modeling of Chinese goral in Saihanwula National Nature Reserve. Journal of Beijing Forestry University, 41, 102-108 (2019).

34. Zheng, H., Gao, J., Teng, Y., Feng, C. \& Tian, M. Temporal variations in soil moisture for three typical vegetation types in Inner Mongolia, Northern China. PLoS One, 10, e0118964 (2015).

35. Dai, X. et al. Are dominant plant species more susceptible to leaf-mining insects? A case study at Saihanwula Nature Reserve, China. Ecology and Evolution, 8, 7633-7648 (2018).

36. Withey, J. C., Bloxton, T. D. \& Marzluff, J. M. Effects of tagging and location error in wildlife radiotelemetry studies in radio tracking and animal populations43-75(Academic Press, 2001).

37. Adrados, C., Girard, I., Gendner, J. P. \& Janeau, G. Global positioning system (GPS) location accuracy improvement due to selective availability removal. Comptes Rendus Biologies, 325, 165-170 (2002).

38. Christiansen, F., Esteban, N., Mortimer, J. A. \& Graeme, H. Diel and seasonal patterns in activity and home range size of green turtles on their foraging grounds revealed by extended Fastloc-GPS tracking. Marine Biology, 164, 10-16 (2017).

39. Van Beest, F. M., Mysterud, A., Loe, L. E. \& Milner, J. M. Forage quantity, quality and depletion as scale-dependent mechanisms driving habitat selection of a large browsing herbivore. Journal of Animal Ecology, 79, 910-922 (2010).

40. Morellet, N. et al. Seasonality, weather and climate affect home range size in roe deer across a wide latitudinal gradient within Europe. Journal Animal Ecology, 82, 1326-1339 (2013).

41. Viana, D. S., Granados, J. E., Fandos, P., Perez, J. M. \& Soriguer, R. C. Linking seasonal home range size with habitat selection and movement in a mountain ungulate. Movement ecology, 6, 1-9 (2018).

42. Amor, J. M. et al. Seasonal home ranges and habitat selection of three elk (Cervus elaphus) herds in North Dakota. PLoS One, 14, e0211650 (2019).

43. Spiegel, O., Leu, S. T., Bull, C. M., Sih, A. \& Chase, J. What's your move? Movement as a link between personality and spatial dynamics in animal populations. Ecology Letter, 20, 3-18 (2017).

44. Seidel, D. P. \& Boyce, M. S. Varied tastes: home range implications of foraging-patch selection. Oikos, 125, 39-49 (2016).

45. Vore, J. M. \& Schmidt, E. M. Movements of female elk during calving season in Northwest Montana. Wildlife Society Bulletin, 29, 720-725 (2001).

46. Cho, C. U., Kim, K. \& Kwon, G. Habitat altitude and home range of the endangered long-tailed goral (Naemorhedus caudatus): seasonal and monthly home range and altitude change. Mammalia, 80, 
481-489 (2016).

47. Yan, W. B., Zeng, Z. G. \& Gong, H. S. Seasonal variation and sexual difference of home ranges by takins. The Journal of Wildlife Management, 81, 938-942 (2017).

48. Luccarini, S. L., Mauri, P. \& Lamberti \& M. Apollonio. Red deer (Cervus elaphus) spatial use in the Italian Alps: home range patterns, seasonal migrations, and effect of snow and winter feeding. Ethology Ecology and Evolution, 18, 127-145 (2006).

49. Carvalho, P., Nogueira, A. J. A. \& Soares, A. M. V. M. \& C. Fonseca. Ranging behavior of translocated roe deer in a Mediterranean habitat: seasonal and altitudinal influences on home range size patterns of range use., 72, 89-94 (2008).

50. Yang, J., Chen, Z. J. \& Wu, L. J. Preliminary observation on behavioral rhythm of Naemorhedus griseus in Inner Mongolia Saihanwula National Nature Reserve. Sichuan Journal of Zoology, 38, 1-7 (2019).

51. Fieberg, J. \& Borger, L. Could you please phrase "home range" as a question? Journal of Mammal, 93, 890-902 (2012).

52. Gula, R. \& Theuerkauf, J. The need for standardization in wildlife science: home range estimators as an example. European Journal of Wildlife Research, 59, 713-718 (2013).

53. Huck, M., Davison, J. \& Roper, T. J. Comparison of two sampling protocols and four home-range estimators using radio-tracking data from urban badgers Meles meles. Wildlife Biology, 14, 467-477 (2008).

54. Tang, S. P., Li, C. H., Liu, W., Wu, L. J. \& Bao, W. D. Viability analysis of Chinese goral population in Saihanwula National Nature Reserve, Inner Mongolia. Scientia Silvae Sinicae, 55, 118-124 (2019).

55. Boyle, S. A., Lourenço, W. C. \& da Silva, L. R. \& Smith A T. Home range estimates vary with sample size and methods. Folia Primatol, 80, 33-42 (2009).

\section{Appendix}

Appendix file is not available with this version.

\section{Figures}




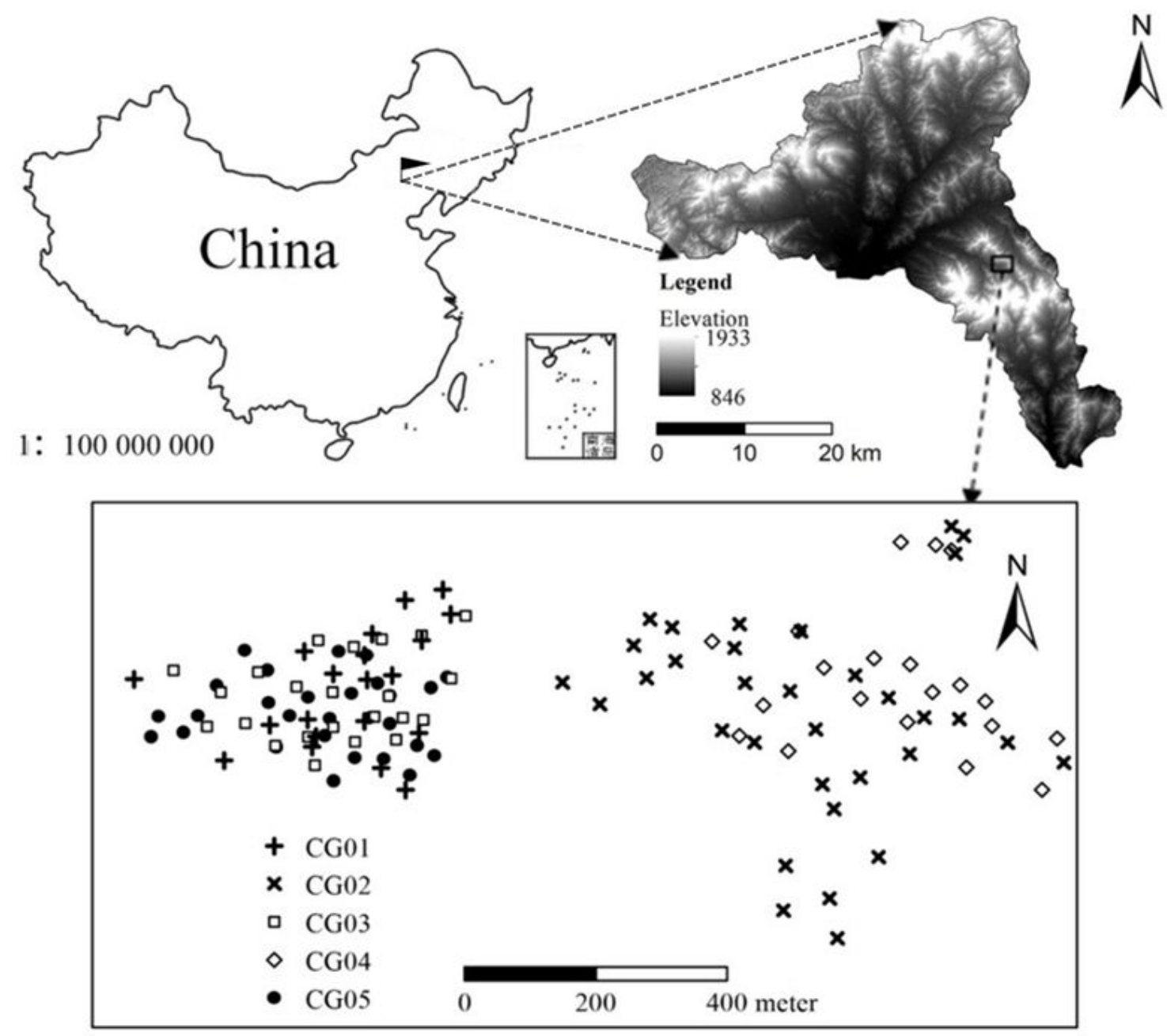

Figure 1

Study area and GPS locations of Chinese goral in Saihanwula National Nature Reserve 


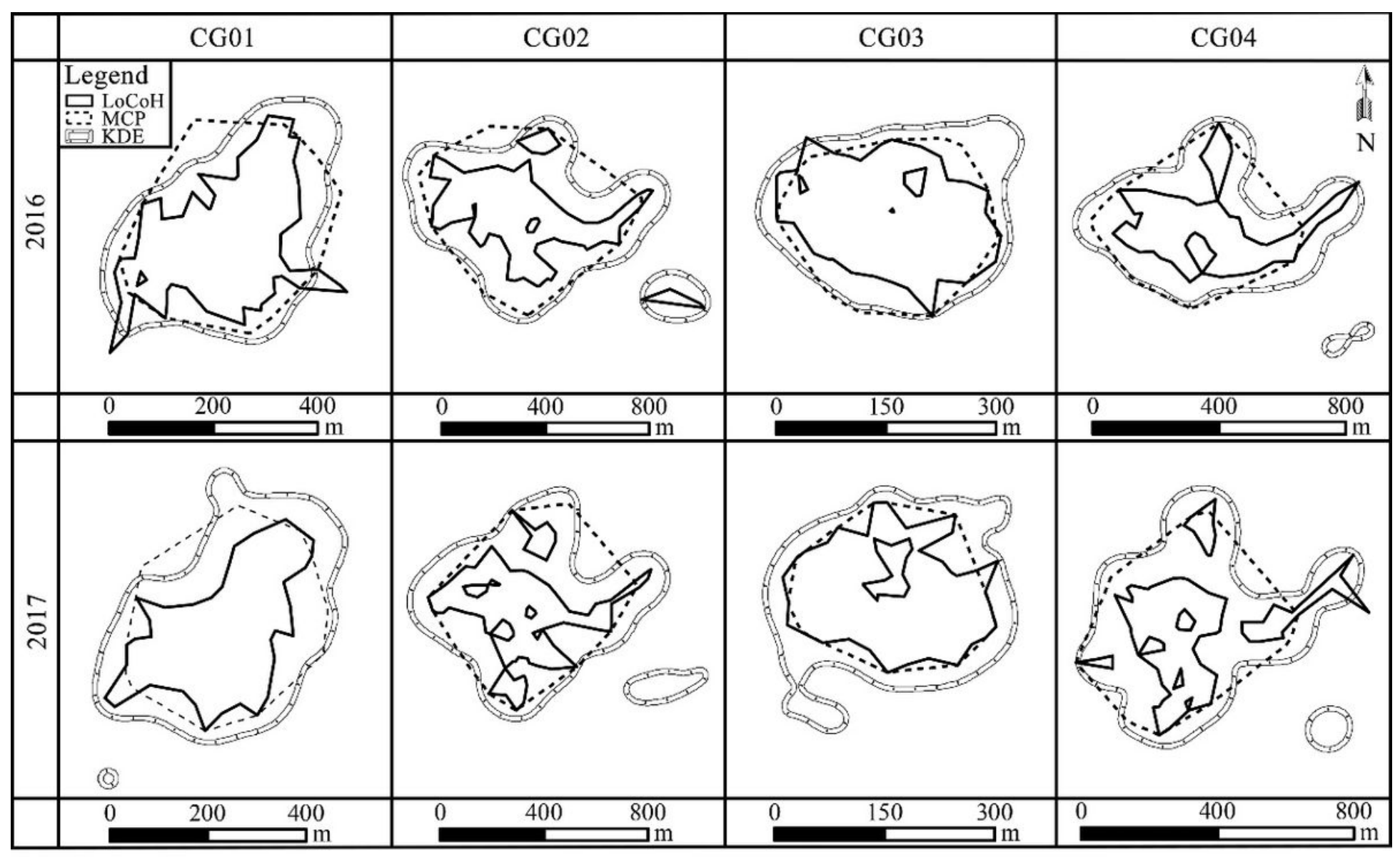

Figure 2

95\% annual home ranges of four goral with three different estimation methods in 2016 and 2017.

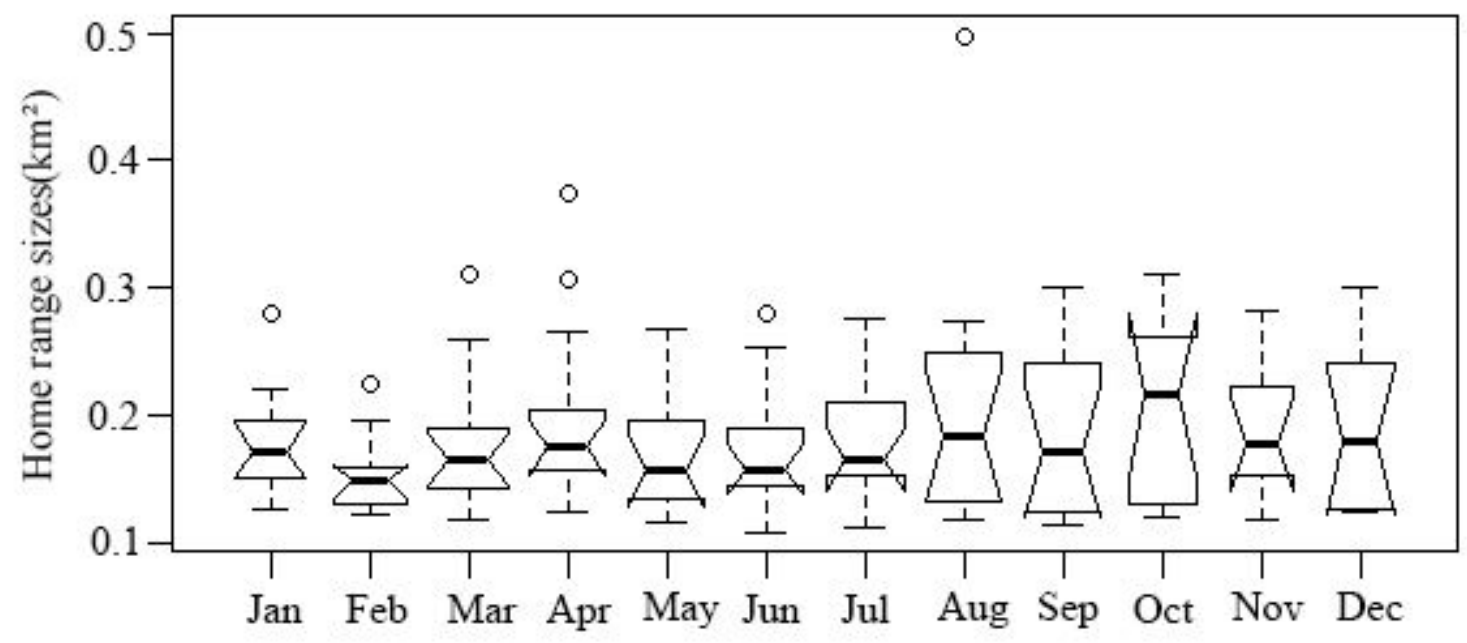

Figure 3

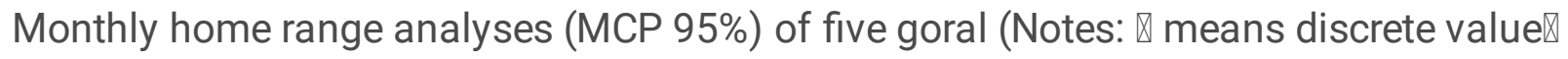

